\title{
Polymeric bile acid sequestrants-Synthesis using conventional methods and new approaches based on "controlled"/living radical polymerization
}

\author{
Patrícia V. Mendonça ${ }^{\mathrm{a}}$, Arménio C. Serra ${ }^{\mathrm{b}}$, Cláudia L. Silva ${ }^{\mathrm{c}}$, \\ Sérgio Simões ${ }^{\mathrm{c}, \mathrm{d}}$, Jorge F.J. Coelho ${ }^{\mathrm{a}, *}$ \\ a Department of Chemical Engineering, University of Coimbra, Polo II, Pinhal de Marrocos, 3030-290 Coimbra, Portugal \\ b Chemistry Department, University of Coimbra, 3004-535 Coimbra, Portugal \\ c Bluepharma, Indústria Farmacêutica, SA, São Martinho do Bispo 3045-016 Coimbra, Portugal \\ d Faculty of Pharmacy, University of Coimbra, 3000-548 Coimbra, Portugal
}

\section{A R T I C L E I N F O}

\section{Article history:}

Received 26 June 2012

Received in revised form 7 September 2012

Accepted 11 September 2012

Available online 18 September 2012

\section{Keywords:}

Bile acid sequestrants

Living radical polymerization

Cholesterol

Drug discovery

Polymers

\begin{abstract}
A B S T R A C T
Polymeric bile acid sequestrants have received increasing attention as therapeutic agents for the treatment of hypercholesterolemia. These materials are usually cationic hydrogels that selectively bind and remove bile acid molecules from the gastrointestinal tract, decreasing plasma cholesterol levels. Due to their high molecular weight, the action of bile acid sequestrants can be limited to the gastrointestinal tract, avoiding systemic exposure, which constitutes an advantage over conventional small-molecule drugs.

Different polymers, such as vinyl polymers, acrylic polymers and allyl polymers have been used to prepare potential bile acid sequestrants based on conventional polymerization techniques. Also, much effort has been devoted to understanding the structure-property relationships between these polymers and their ability to bind bile acid molecules. The efficacy of these polymeric drugs can be ascribed to five major variables: (i) the density of cationic charges, (ii) the length and distribution of the hydrophobic chains, (iii) the polymer backbone flexibility, (iv) the degree of cross-linking and (v) the polymer shape.

This review summarizes the major synthesis pathways that are employed in the preparation of this type of polymer therapeutics and the polymer structural key factors that are of relevance to enhanced therapeutic efficacy. Herein, new synthesis approaches, based on "controlled"/living radical polymerization techniques, are highlighted.
\end{abstract}

(c) 2012 Elsevier Ltd. All rights reserved.

\section{Contents}

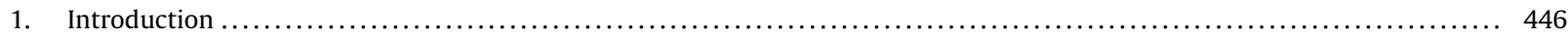

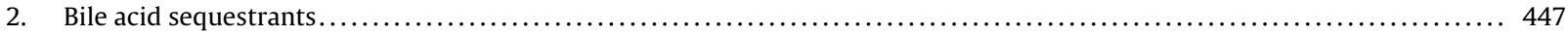

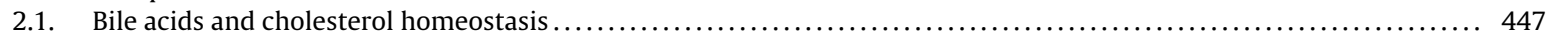

\footnotetext{
Abbreviations: ATRP, atom transfer radical polymerization; BAS, bile acid sequestrants; CLRP, "controlled"/living radical polymerization; CVD, cardiovascular disease; FDA, Food and Drug Administration; FRP, free radical polymerization; GI, gastrointestinal; LDL, low density lipoprotein; LDL-C, low density lipoprotein cholesterol; RAFT, reversible addition-fragmentation chain transfer; SEM, scanning electron microscopy; TEM, transmission electron microscopy; UV, ultraviolet.

* Corresponding author. Fax: +351 239798703.

E-mail addresses: patmend@eq.uc.pt (P.V. Mendonça), armenio.serra@gmail.com (A.C. Serra), csilva@bluepharma.pt (C.L. Silva), ssimoes@bluepharma.pt (S. Simões), jcoelho@eq.uc.pt (J.F.J. Coelho).
} 


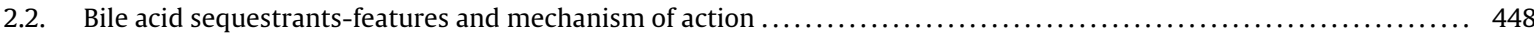

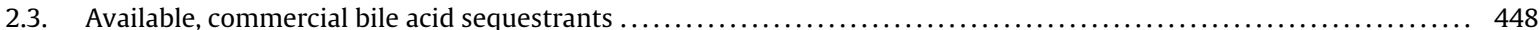

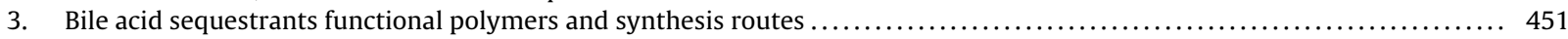

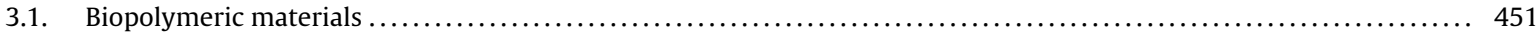

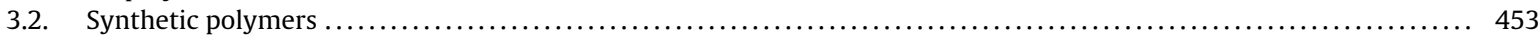

3.3. New approach towards well-defined bile acid sequestrants - "controlled"/living radical polymerization ............ 457

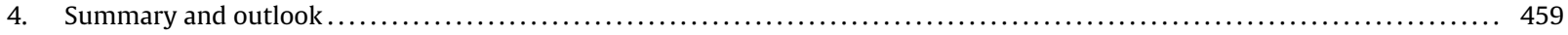

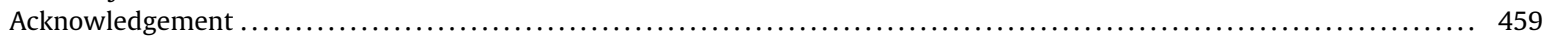

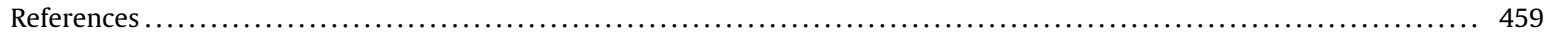

\section{Introduction}

The use of polymeric materials in the pharmaceutical and medical fields have received great attention during recent years due to their distinctive physico-chemical characteristics, such as their biocompatibility and their appropriate mechanical properties. Polymers have been used for a wide range of applications in the biomedical area, namely in drug delivery systems, as components of artificial organs, in the delivery of antibodies and in medical devices, among others [1].

Recent progresses in this field has led to the development of a new class of drugs, namely polymer therapeutics [2], which can be divided in two major types according to the polymer function. These include polymers used as vehicles for targeted drug delivery and polymers with intrinsic therapeutic activity [3]. Examples of polymer therapeutics are polymer-drug combinations (pro-drugs), polymer-protein conjugates (bioconjugates) and polymers with sequestration properties [4]. Polymeric drug delivery systems have been extensively studied and there are many interesting reviews on this. However, reviews dealing with polymeric therapeutics are very few and recent $[3,5]$.

The use of polymers as therapeutic agents is of great interest and offers considerable potential since they present some advantages in comparison to small molecule drugs. These advantages include long-term safety profiles, lower toxicity, the capacity to recognize and to bind molecular components and their polyvalence (raising the possibility of multiple interactions with the disease species) [3]. Furthermore, the structure of the polymers can be designed and the polymers functionalized with many different pendant molecules, leading to materials with different biological activities than those of conventional drugs. In addition, the action of these polymers can be limited to the gastrointestinal (GI) tract, since their high molecular weight prevents their absorption into the systemic circulation [1]. Therefore, polymers can be used to bind selectively and to remove detrimental molecules from the GI tract and also to eliminate viruses, toxins and bacteria. These polymers properties constitute an advantage in treatments in which systemic exposure of the drug is undesirable [6]. Through the manipulation of polymer structure and the incorporation of appropriate functional groups, it is possible to develop polymer therapeutics with high selectivity and potency towards specific molecules - polymer sequestrants [5]. In recent years, different polymer sequestrants have been developed to bind and to remove species that cause diseases, such as phosphate ions (renal diseases), potassium ions (hyperkalemia), iron salts/complexes (iron overload disorders) and toxins [7], among others [1,3]. Some of these polymer therapeutics are currently available, exhibiting and providing healing benefits at acceptable therapeutic doses [4]. Particular interest is devoted to the use of this approach to create materials that have the ability to sequester bile acid molecules, the so-called bile acids sequestrants (BAS).

BAS have an important application in the control of the blood cholesterol level, a major cardiovascular disease (CVD) risk factor, which is a leading cause of death, an increasing source of morbidity and a major factor in disability and ill-health, especially in the industrialized countries [8]. Commonly, cholesterol lowering drugs are based on statins, cholesterol absorption inhibitors, which rely on a different treatment strategy than BAS [6,9]. Statins act directly on the cholesterol conversion process into bile acids by inhibiting the HMG-CoA reductase (ratecontrolling enzyme in the cholesterol production process), while cholesterol absorption inhibitors have the ability to reduce the intestinal absorption of dietary and biliary cholesterol at the level of the brush border of the intestine. On the other hand, BAS operate in an indirect way by capturing bile acids in the small intestine, which causes an organism response that leads to cholesterol consumption and, ultimately, to the reduction of the blood-cholesterol level. Due to their mechanism of action, BAS present some advantages in comparison to other therapies. For instance, statins therapy (the first line of treatment) is not advised in pregnant women, nursing mothers and patients with significant hepatic dysfunction $[1,10]$. Moreover, in about $10 \%$ of patients, long-term complications can arise such as liver dysfunction and musculoskeletal symptoms [10]. These are the more common reasons for statins discontinuation [1]. Thus, it is of utmost importance that new and more efficient BAS are developed for patients that cannot use statins or must take high statin doses. However, the presence of such polymeric therapeutics in the market is very limited at present.

The aim of this review is to present and to critically discuss the synthesis routes that are available for the preparation of BAS with a particular emphasis on future perspectives in this field, based on advanced 
<smiles>C[C@H](CCC(=O)O)[C@H]1CC[C@H]2[C@H]3[C@H](C[C@H](O)[C@@]21C)[C@@]1(C)CC[C@H](O)C[C@@H]1C[C@H]3O</smiles>

Cholic acid<smiles>C[C@H](CCC(=O)O)[C@H]1CC[C@H]2[C@@H]3CC[C@H]4C[C@@H](O)CC[C@]4(C)[C@H]3C[C@H](O)[C@@]21C</smiles>

Deoxycholic acid<smiles>C[C@H](CCC(=O)O)[C@H]1CC[C@H]2[C@H]3[C@H](CC[C@@]21C)[C@@]1(C)CC[C@H](O)C[C@@H]1C[C@H]3O</smiles>

Chenodeoxycholic acid<smiles>C[C@H](CCC(=O)O)[C@H]1CC[C@H]2[C@@H]3CC[C@H]4C[C@@H](O)CC[C@]4(C)[C@H]3CC[C@@]21C</smiles>

Lithocholic acid

Fig. 1. Chemical structures of bile acids.

polymerization techniques, namely “controlled"/living radical polymerization (CLRP) techniques.

\section{Bile acid sequestrants}

\subsection{Bile acids and cholesterol homeostasis}

Bile acids are cholesterol based amphiphilic molecules produced in the liver. They act as biological surfactants aiding food digestion and absorption of lipids in the GI tract [4]. In addition, bile acids control several metabolic processes such as the breakdown of glucose and triglycerides, the provision of energy triglyceride and principally, the control of cholesterol homeostasis [11].

Cholesterol is excreted from the body through the bile as free cholesterol or in the form of bile acids, after a conversion process [12]. Nearly 50\% of the cholesterol catabolism is governed by its conversion into bile acids $[11,13]$. The first reaction of this process is catalyzed by the hepatic microsomal cholesterol $7 \alpha$-hydroxylase, leading to the formation of primary bile acids, (cholic acid and chenodeoxycholic acid in humans). The second step is based on the conversion of the primary bile acids into deoxycholic acid and lithocholic acid (secondary bile acids), by the action of intestinal bacteria flora $[11,12]$. The bile acids that are presented in the bile consist largely of $30-40 \%$ of cholic acid, $30-40 \%$ of chenodeoxycholic acid, $20-25 \%$ of deoxycholic acid and 1-2\% of lithocholic acid (Fig. 1) [12].

Bile acids are synthesized in the parenchymal cells (hepatocytes) of the liver and are stored in the gall bladder, that releases the bile through the bile duct into the GI lumen, upon ingestion of a meal [6]. Subsequently, the bile acids enter into the intestine lumen to aid food digestion being, the most part, further reabsorbed by the distal ileum, returning to the liver via portal circulation, in a process known as the enterohepatic cycle (Fig. 2) [11]. In this cycle, there is a small amount (nearly 5\%) of bile acids that can be lost through feces excretion. This loss is compensated for by the synthesis of new bile acids in the liver. The mixture of bile acids present in the body is very complex since they are commonly conjugated with the amino

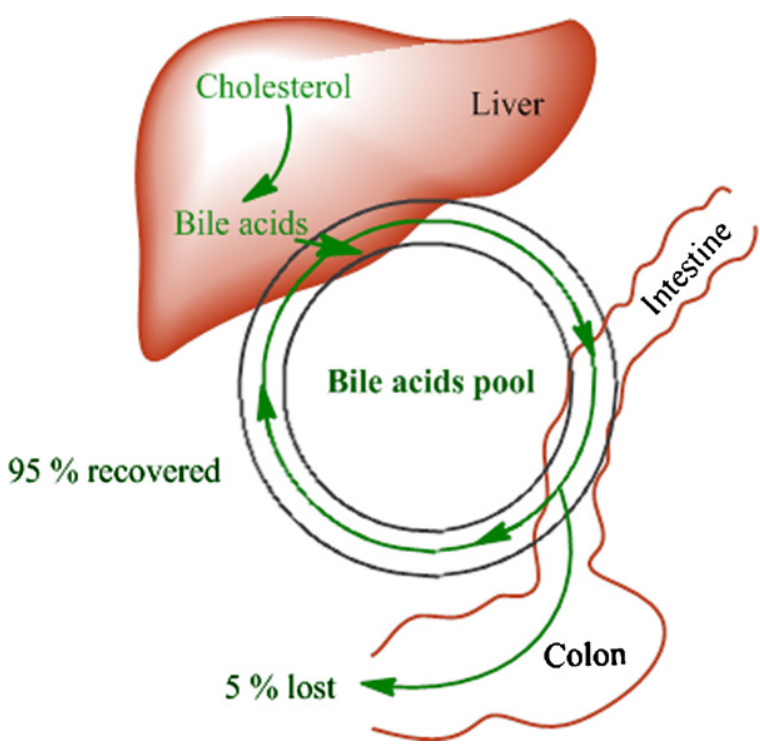

Fig. 2. Illustration of the enterohepatic cycle. 
acids taurine and glycine, (ratio of taurine/glycine $=1 / 3$ ) [14,15]. The $\mathrm{p} K_{\mathrm{a}}$ of bile acids is between 2 and 5 and so, under the conditions that prevail in the small intestine ( $\mathrm{pH}=7.0-9.0)$, these molecules are in their ionized form (also called bile salts) [16].

\subsection{Bile acid sequestrants-features and mechanism of action}

Hypercholesteremia is one of the more important risk factors for coronary heart disease, a health issue that affects millions of people around the world, especially in the developed countries. As previously mentioned, BAS can be used as cholesterol reducing agents without having the problems associated with the long-term systemic exposure to statins.

Usually, BAS are cationic polymeric hydrogels that bind the negatively charged bile acids in the small intestine, avoiding their reabsorption, and causing fecal bile acid excretion. This loss of bile acids induces the conversion of cholesterol into bile within the liver, which promotes an increase in low density lipoprotein (LDL) receptors and the increased clearance of low density lipoprotein cholesterol (LDL-C) from the circulation system [17]. BAS bind bile acids mainly by electrostatic interactions and hydrophobic interactions $[4,18]$. The chemical structure of bile acids consists of a hydrophobic core (steroid skeleton) and a hydrophilic anionic segment. For this reason, an efficient BAS must have positive charges within its structure and a maximized hydrophobicity, while maintaining sufficient hydrophilicity to provide appropriate swelling characteristics in physiologic environments. Also, an appropriate density of cationic charges is required to ensure the occurrence of electrostatic interactions (the primary interactions of the binding process) with anionic bile acids [19]. For this purpose, the use of synthetic methods that result in the creation of polymers that possess the appropriate controlled structure, architecture and functionality is of extreme importance.

Additionally, BAS have shown benefits beyond controlling high cholesterol levels. One of the more significant is the ability to reduce the fasting blood glucose and to decrease hemoglobin A1c in diabetic patients. Although the mechanism of action is not completely clear [9], it is expected that these polymer therapeutics may also have a very important role in the treatment of hypercholesterolemic patients that present type II diabetes.

\subsection{Available, commercial bile acid sequestrants}

BAS have been used for about thirty years [17] to decrease cholesterol blood levels in humans. Scientific research has led to the development of several products [20-23], however exhibiting lower clinical efficacy compared to statins. Three examples that are approved by Food and Drug Administration (FDA) for hypercholesterolemia treatment and are on the US market are (a) cholestyramine, (b) colestipol and (c) colesevelam [13,24]. Two other BAS compositions are commercially available. These are (d) colextran in Spain and Italy and (e) colestilan (also known as colestimide) in Japan [25,26] (Table 1 and Fig. 3 ).
Cholestyramine and colestipol are two first-generation products of BAS. In the case of cholestyramine, the binding capacity towards bile acid molecules was recognized only after their commercialization as an anion exchange resin [18].

Cholestyramine is a cationic hydrogel that is based on poly(styrene) that is partly cross-linked with divinylbenzene (2\%), giving polymers with molecular weights that are greater than $10^{6} \mathrm{~g} / \mathrm{mol}$ and swelling ratios (amount of water uptake per gram of dry polymer) of approximately $2.5 \mathrm{~g} / \mathrm{g}[18,27]$. This product can be prepared by the chloromethylation of the polymer, followed by quaternization of the hydrogel with trimethylamine, ( 4 meq of cationic groups per gram of dry polymer) [28]. Colestipol is a condensation polymer produced by the step-growth polymerization of diethylenetriamine and epichlorohydrin and is commercialized as its hydrochloride salt (Fig. 3). Due to the type of functional groups that are present in the colestipol structure (secondary and tertiary amines), the efficacy of this BAS is more dependent on the $\mathrm{pH}$ of the medium than is that of cholestyramine, which has a permanent positively charged quaternary ammonium ion. However, with regard to the $\mathrm{pH}$ of the small intestine, most of the secondary amines and tertiary amines that have a $\mathrm{p} K_{\mathrm{a}}$ value in the range from 9.0 to 10.5 [29] should be ionized. Despite the differences in their molecular structures, cholestyramine and colestipol present the same order of clinical efficacies. As an example, the cholestyramine binding capacity has been reported as being $1.8-2.2 \mathrm{~g}$ of sodium glycocholate per $g$ of dry polymer (see Table 1) [26]. Cholestyramine and colestipol bind and remove preferentially dihydroxy bile acids from the GI tract [17]. Since the liver produces a mixture of dihydroxy compounds and trihydroxy compounds and although only the dihydroxy compounds are removed significantly, the content of the trihydroxy acids in the bile acids pool increases over the time. This fact leads inevitably to a decrease in the cholestyramine and colestipol efficacies.

In fact, the low binding capacity towards trihydroxy acids is the main reason for the low efficacy of cholestyramine and colestipol [31]. Adverse effects, that have been reported to involve these two BAS are related to their complexation with fat-soluble vitamins, a decrease in the absorption of some other drugs and to GI distress (e.g., dyspepsia, nausea and constipation) [17]. In addition, these BAS present poor patient compliance and the need to be administered in high doses; it is necessary to take $16-24 \mathrm{~g} /$ day to reduce the cholesterol level by $20 \%$ [19]. Part of this inefficiency is also due to the competition between the BAS and the active bile acids reuptake transporter system of the GI tract [6]. In order to overcome this limitation, it is necessary to create BAS molecules with a greater binding strength and affinity towards bile acids.

Colextran, a modified dextran, is an ion exchange resin that exhibits some efficacy in reducing total cholesterol blood levels as well as reducing triglyceridemia in patients presenting with type II and type IV hypercholesterolemia [18].

The second-generation of BAS, represented by colesevelam hydrochloride and colestilan, was specifically designed to have a greater affinity for the binding of bile acids with 
Table 1

Commercially available BAS.

\begin{tabular}{|c|c|c|c|c|c|c|}
\hline BAS & Approval date & Brand name & Molecular name & $\begin{array}{l}\text { Binding capacity ( } \mathrm{g} \text { of bile } \\
\text { acid/g of polymer) }\end{array}$ & $\begin{array}{l}\text { Therapeutic } \\
\text { dose (g/day) }\end{array}$ & Reference \\
\hline Cholestyramine & $1973(\mathrm{FDA})$ & $\begin{array}{l}\text { Questran }^{\circledR} \\
\text { Efensol }^{\circledR} \\
\text { Prevalite }^{\circledR} \\
\text { Ipocol }^{\circledR} \\
\text { Vasosan }^{\circledR} \\
\text { Quantalan }^{\circledR}\end{array}$ & Poly(styrenebenzyltrimethylamoniumchloride) & $1.8-2.2 \mathrm{ga}^{\mathrm{a}}$ & $12-24$ & {$[17,26]$} \\
\hline Colestipol & 1977 (FDA) & $\begin{array}{l}\text { Colestid }^{\circledR} \\
\text { Lestid }^{\circledast} \\
\text { Cholestabyl }^{\circledR}\end{array}$ & $\begin{array}{l}\mathrm{N}^{\prime} \text {-(2-aminoethyl)-N-[2-(2- } \\
\text { aminoethylamino)ethyl]ethane-1,2-diamine } \\
\text { 2-(chloromethyl)oxirane hydrochloride }\end{array}$ & $0.5-0.7 \mathrm{~g}^{\mathrm{a}}$ & $5-30$ & {$[17,26]$} \\
\hline Colextran & 1985 (Spain) & $\begin{array}{l}\text { Dexide }^{\circledR} \\
\text { Pulsar }^{\circledR} \\
\text { Rationale }^{\circledR}\end{array}$ & $\begin{array}{l}\text { Diethylaminoethyl- } \\
\text { dextran } \\
\text { hydrochloride }\end{array}$ & $\mathrm{b}$ & $2-3$ & {$[26]$} \\
\hline Colestilan & 1999 (Japan) & Cholebine $^{\circledR}$ & $\begin{array}{l}\text { 2-Methylimidazole polymer with } \\
\text { 1-chloro-2,3-epoxypropane }\end{array}$ & $\begin{array}{l}2.3 \mathrm{~g}^{\mathrm{c}} \\
2.4 \mathrm{~g}^{\mathrm{d}}\end{array}$ & 3 & {$[26,30]$} \\
\hline Colesevelam & 2000 (FDA) & $\begin{array}{l}\text { Welchol }^{\circledR} \\
\text { Cholestagel }^{\circledR}\end{array}$ & $\begin{array}{l}\text { Allylamine polymer with } \\
\text { 1-chloro-2,3-epoxypropane, } \\
\text { [6-(allylamino)-hexyl]trimethylammonium } \\
\text { chloride and N-allyldecylamine, hydrochloride. }\end{array}$ & b & $3.8-4.4$ & {$[26]$} \\
\hline
\end{tabular}

a Determined for sodium glycocholate.

b Not available in the literature.

c Determined for sodium cholate in water at $37^{\circ} \mathrm{C}$.

${ }^{d}$ Determined for sodium deoxycholate in water at $37^{\circ} \mathrm{C}$. 
<smiles>CCCC(CC(C)c1ccc(C[N+](C)(C)Cl)cc1)c1ccc(C=O)cc1</smiles>

(a)

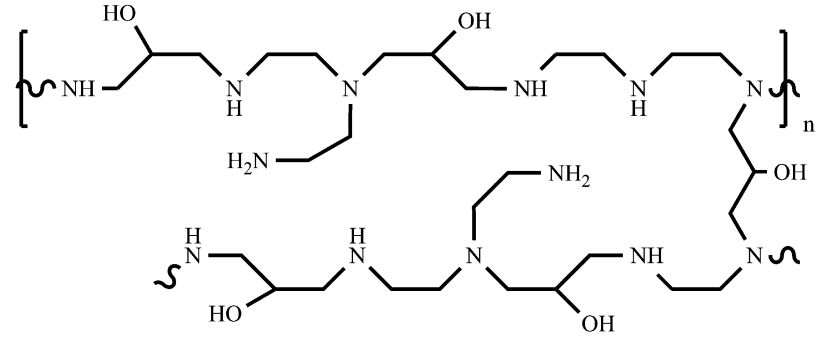

(b)

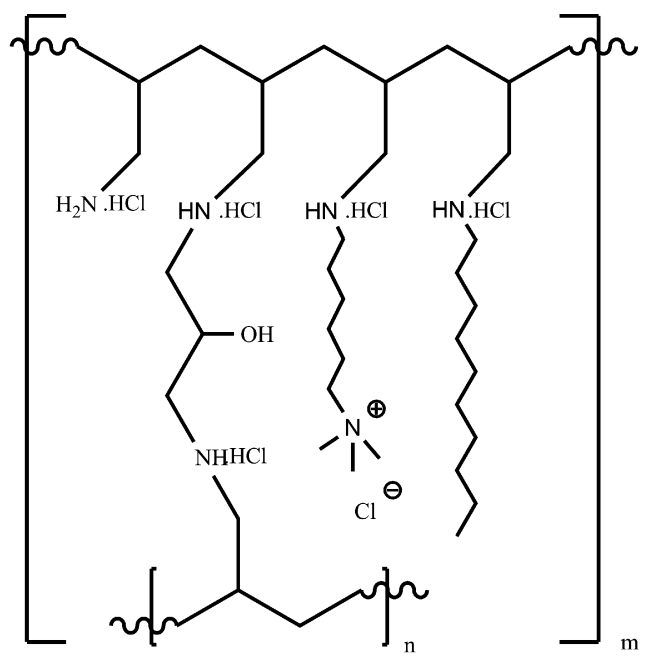

(c)

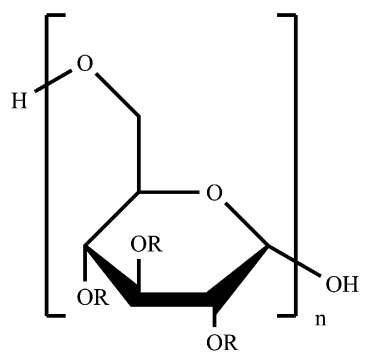

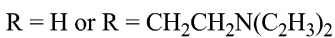

(d)<smiles></smiles>

(e)

Fig. 3. Chemical structures of the commercially available BAS: (a) cholestyramine; (b) colestipol; (c) colesevelam; (d) colextran; (e) colestilan.

fewer side effects [19,32]. Colesevelam was approved by the FDA in 2000 for the treatment of hypercholesterolemia, either as a monotherapy, or in combination with statins. Since then, colesevelam has been approved by the FDA for treatments, as an adjunct to diet, exercise, and other antidiabetic drugs, to improve glycemic control in patients with type II diabetes. Another clinical indication is the treatment of familial hypercholesterolemia in boys and in postmenarchal girls, in the age range from 10 to 17 years, as a monotherapy or in combination with a statin. The chemical structure of colesevelam is substantially different from those of the first generation BAS since it includes spaced, long hydrophobic chains, with protonated primary amines, at the intestine environment $\mathrm{pH}$, that establish electrostatic interactions with the bile acids molecules and quaternary amines that stabilize the hydrogel [17,33]. Additionally, 
the cross-linked epichlorohydrin-based structure reduces the possibility of systemic absorption while decreasing the interactions with the GI tract lining. In comparison with cholestyramine and colestipol, colesevelam hydrochloride exhibits less side effects, these mainly being minimal constipation and GI irritation [34,35] due to its improved water retaining characteristics that create a soft, gelatinous-like material [33]. Another important feature is related to the dose decrease to $2-16 \mathrm{~g} /$ day [17]. In vivo experiments (using hamsters) have shown that colesevelam is three times more efficient than conventional BAS in bile acids sequestration. Due to its structure, colesevelam has affinity to both dihydroxy and trihydroxy bile acids which enhances the clinical efficacy in long-term treatments [33].

Colestilan is a BAS that has imidazolium salt units, derived from the cross-linking reaction between poly(2methylimidazole) and epichlorohydrin. Its clinical pharmacological effects are similar to those exhibited by cholestyramine, at approximately one quarter of the dose (Fig. 3) [30]. In vitro adsorption studies have been used to demonstrate the superior binding capacity of colestilan when compared with cholestyramine, probably related to the 1.6 times greater ion exchange capacity [30] and a higher swelling capacity in water, making the binding sites more accessible to the bile acids. It has also been shown that colestilan has a lower rate of adsorption to other drugs than that given by cholestyramine [36]. Even though, colestilan exhibits a greater affinity for binding bile acids than cholesthyramine, a steric hindrance effect that is due to the hydroxyl group on the steroid ring, seems to be a serious limiting factor for the adsorption of bile salts by this polymeric therapeutic molecular system.

Despite the advantages of the second generation of BAS that have been identified, such as improved efficacy, better tolerance, reduced side effects and reduced drug interactions, further developments in the BAS synthesis field are still needed in order to enhance the specificity of the polymers towards bile acid molecules. By this means, it should be possible to reduce common undesirable side effects (e.g., stomach distress), to enhance the therapeutic efficacy of the polymer therapeutics, to reduce the dose and to improve patient compliance.

\section{Bile acid sequestrants functional polymers and synthesis routes}

Over the last decade, different materials have been tested, both in vivo and in vitro, for their binding of bile acids molecules. These include dietary fibers, antiacids, charcoal and various polymers [37]. Due to their properties (e.g., their high molecular weight and their multiple functionalities) polymeric materials are the most widely studied materials for this application. The more common polymeric structures that are used are cationic hydrogels (with epichlorohydrin as cross-linking agent) based on (meth)acrylates, vinyl polymers, allyl polymers, poly(meth)acrylamides and polyethers. Also used are polymers based on poly(styrene) backbones (as a hydrophobic segment), containing amine/ammonium pendant groups (as a cationic, hydrophilic segment) (Fig. 4) [1,4,6]. The cationic groups ensure the occurrence of electrostatic interactions with the ionized bile acids, the more efficient being usually based on the ammonium group [14,38]. Other cationic groups, such as guanidinium have been tested but have shown poorer results [38]. The polymers hydrophobic segments are used to attract the steroid skeleton of bile acid molecules. The design and synthesis strategies of BAS are based on these two types of interactions (electrostatic and hydrophobic), requiring a balance between the charged groups and the hydrophobic segments in order to achieve the maximum binding capacity. It is also necessary to take into account the competing desorbing forces that are present in the GI tract and the time limiting factor in binding bile acids (the small intestine transit time for pharmaceutical dosages is $3 \pm 1 \mathrm{~h}$ ) [14]. Therefore, an efficient polymeric BAS must exhibit a high binding capacity (number of binding sites) and a strong binding strength (force required to separate the bile acids from the BAS) as well as selectivity towards bile acid molecules [19]. Other key factors in the design of BAS are polymer backbone flexibility (needed to provide the appropriate swelling properties) and the relative position of the cationic groups (needed to prevent intra-polymeric interactions) [39].

In vitro studies that are related to monitoring binding mechanisms are usually performed through the use of isotherms of sorption [18]. BAS polymer samples are kept in contact with bile acid salts (individual or combination) solutions at a constant temperature and a constant $\mathrm{pH}$. In general, the equilibrium concentration of bile acids is measured by high performance liquid chromatography (HPLC)-related techniques that allow the rapid separation and quantification of the compounds [15]. In vivo studies, normally with hamsters as the animal model, are also used and can give more realistic results, since it is very difficult to mimic intestinal physiological conditions in the laboratory. The results obtained from the binding experiments are of extreme importance since they provide relevant information with respect to the design of molecular structures that possess the suitable properties that are needed for them to be considered as efficient BAS materials.

\subsection{Biopolymeric materials}

Fibers constitute an important part of the daily diet of humans, corresponding to polymer-based carbohydrate materials that are resistant to the digestion process, including both soluble fibers and insoluble fibers $[41,42]$. These biopolymeric materials have been shown to be capable of binding bile acid molecules both in in vitro experiments [41-47] and in in vivo experiments [48-50]. The advantages of its consumption to human health are amply claimed [51,52]. However, studies in humans have shown that the extent of cholesterol level reduction that is due to fiber consumption, can be very limited [53,54]. Recent studies have been used to prove the ability of several types of food to bind bile acids, these foods having a binding capacity that is substantially lower than that of cholestyramine [55-58]. Moreover, the binding activity of dietary fiber products has also been determined for bile acids that are in a glycoconjugated form [59]. The enzymatic modification of dietary fibers and/or their chemical modification can lead to an improvement of the binding capacity [60] 


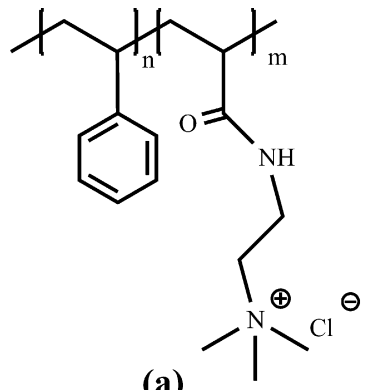

(a)

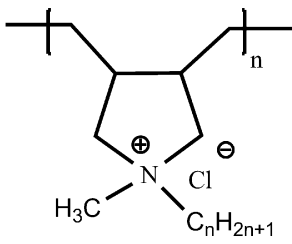

(b)

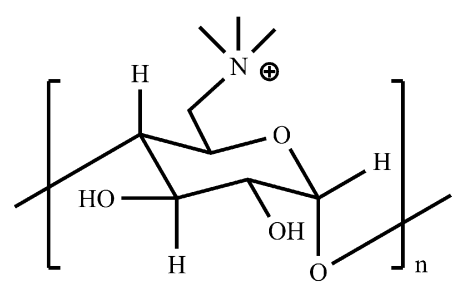

(c)

Fig. 4. Chemical structures of representative BAS reported in the literature: (a) polystyrene-b-poly(N,N,N-trimethylammoniumethylene acrylamide chloride) [40]; (b) N-alkyl-N-methyldiallylammonium salt [19]; (c) quaternized amino methylan [14].

as can a simple transformation, such as that brought about by steam cooking $[61,62]$. The bile acids binding capacity of water soluble and of water insoluble dietary fibers can be predicted by a simplified model that was developed by Zacherl and co-authors. This model correlates the binding capacity with the fiber viscosity after digestion [63]. It was shown that an increased viscosity of the fiber-containing medium leads to an increase of the binding capacity towards bile acid molecules. However, this correlation was not verified when the viscosity of oat fiber-based slurries was intentionally diminished, showing that the binding mechanism could also be regulated by other interactions, such as hydrophobic interactions. Besides bile acids removal, other effects such as the inhibition of the intestinal absorption [64] or the increased excretion [65-67] of cholesterol can be also promoted by these fibers.

Other types of biopolymers, including polysaccharides, have been used as a starting material to produce BAS due to their biocompatibility, low toxicity, hydrophilicity [27] and the presence of hydroxyl groups that can be easily functionalized. $\beta$-Cyclodextrin is an oligosaccharide that is composed of seven glucose units that are linked in a cyclic structure and has been reported to have showed hypolipidemic and hypocholesterolemic effects in animals [13]. The mechanism of action of these polymers involves the absorption of lipids and the increase of fecal excretion. Zhu's research group has synthesized cross-linked, aminated $\beta$-cyclodextrin polymers, with a degree of crosslinking ranging from 14 to $20 \%$ [68]. The hydrophobic cavity and hydrophilic exterior segments that were available in the polymer structure were able to facilitate the binding of the bile acids, by the creation of inclusion complexes. The size of the cavity was found to be an important parameter since the binding capacity was lower towards more hydrophilic bile acids (greater content of hydroxyl groups in the structure), due to steric hindrance. Functionalization of the polymers was achieved by introducing alkylammonium groups through tosylation, followed by treatment with trimethylamine. However, the reaction presented low efficiencies ( 1 functional group per 5 units of $\beta$-cyclodextrin). The binding capacity of the prepared materials was evaluated in the presence of bile salts with their different hydrophobic characters, in a temperature range of $10-50^{\circ} \mathrm{C}$. Despite the low degree of functionalization, the authors found that the presence of the quaternary ammonium groups in the polymer structure enhanced their binding capacity, suggesting that electrostatic interactions play an important role in the complexation process. However, this component becomes of less relevance when the temperature is increased [68]. Also, an increase in the degree of cross-linking of the hydrogels led to a decrease in the binding capacity, since the $\beta$-cyclodextrin cavity is less available for the interactions. The maximum binding capacity of the functionalized $\beta$-cyclodextrin was close to $0.3 \mathrm{mmol} / \mathrm{g}$ ( $\mathrm{mmol}$ of bile acids per gram of dry polymer).

Dextran hydrogels that were modified with alkylammonium groups have been used to study the extent of correlation between the hydrophobic character of BAS networks and their binding capacity [27,39,69]. In the study, dextran spherical particles (molecular weight of $70000 \mathrm{~g} / \mathrm{mol}$ ) or linear dextran (molecular weight of $30000 \mathrm{~g} / \mathrm{mol}$ ) were cross-linked with epichlorohydrin and functionalized with $N, N$-dimethyl- $N$-alkyl ammonium chloride groups, with an extent of functionalization of approximately $20 \%$. This value corresponds to a defined balance between the repulsive electrostatic forces and the hydrophobic interactions. The degree of cross-linking was optimized to afford hydrogels that were able to take up $3-4 \mathrm{~g}$ of water, at equilibrium, per gram of dry polymer [70]. By varying the alkyl chain length, the authors showed that the binding process could be regulated by different mechanisms depending on the hydrophobic character of the BAS network [39]. For alkyl chains that were greater in length than the equivalent of a $C_{4}$ chain sequence, the sequestration of bile acids took place by mixed micelle formation, with domination of the hydrophobic interactions between the polymer and the steroid skeleton of the bile acids while, for shorter chain lengths, the binding process was found to be regulated by the electrostatic interactions of the ammonium groups. In these hydrogels, hydrophobic interactions seem to play a very important role in the bile acids adsorption originating materials that have a greater binding capacity than that shown by cholestyramine.

Lee and co-workers, using modified methylans (polysaccharides whose molecular weight was greater than $10^{5} \mathrm{~g} / \mathrm{mol}$ ) [14] prepared mixtures of bile acids in order to simulate an intestinal environment. They then measured the binding capacity of these polymers using HPLC [14]. The polymers exhibited binding capacities that were greater than those of cholestyramine. However, these materials presented the same limitation that was 
exhibited by conventional BAS, which is the poor affinity towards trihydroxy bile acids in comparison to the more hydrophobic dihydroxy acids. This result emphasizes the importance of hydrophobic interactions to the bile acids sequestration process.

Chitosan is a glucosamine-based polymer that is derived from the deacetylation of chitin. Chitosan can be considered to be an interesting starting polymer from which to prepare BAS. This biopolymer is not digestible by humans and presents good biocompatibility and safety. Chitosan was first tried in the deacetylated form in animal studies and proved to have good hypocholesterolemic action, to an extent that was comparable with that of cholestyramine [71-75]. Zhou and co-authors studied several samples of chitosan with different molecular weights and degrees of deacetylation in order to establish a possible correlation between the properties of the polymers and their binding capacity [75]. However, under the experimental conditions used, it was not possible to establish any relationship that could predict the polymers efficiency as BAS. In comparison to the cholestyramine binding capacity, chitosan hydrolysates, having molecular weight between $5000 \mathrm{~g} / \mathrm{mol}$ and $20000 \mathrm{~g} / \mathrm{mol}$ [76] and as well as changes of chitosan structure by quaternization of the amino groups [77], provided materials with greater efficiency. This biopolymer was modified so that it contained diethylaminoethyl groups in its structure, giving rise to a material that possessed a greater bile acids absorption capacity, especially for deoxycholate [78]. Another interesting and successful approach is the use of organic acid salts of chitosan [79,80]. In this case, the absorption of bile acids occurs by ionic exchange with the displacement of the anion of the acid.

\subsection{Synthetic polymers}

In an attempt to design the appropriate polymer structure for an efficient BAS and to understand their binding mechanism with bile acids, many authors have used synthetic polymers, with different functionalities and structures $[40,81,82]$.

One strategy that is commonly followed for the preparation of polymeric BAS is that of the modification of commercial BAS polymer backbones, such as polyamines (similar structures of colestipol and colesevelam) [69]. Figuly and co-workers have reported the synthesis of 61 different poly(alkylamine)-based polymer networks, prepared by the reaction of several (di)amines with dihalo compounds or diepoxides, in different solvents/mixtures [83]. The swelling behavior of the resulting hydrogels was influenced by the polymer stiffness, the polar nature of the polymer and the degree of cross-linking. A high polarity (as ammonium salt), great polymer flexibility and a low degree of cross-linking lead to polymers with an enhanced swelling capacity. Preliminary in vitro binding experiments based on methyl cholate were used to demonstrate that hydrogels formed by diamines and $\alpha, \omega$-dibromoalkanes are more efficient than cholestyramine. Considering the main structure of cholestyramine (polystyrene cross-linked with divinylbenzene), Zhang and colleagues reported a new approach to BAS synthesis. This was based on the bio-conjugation of the polymer with the bile acid molecules [82].

Bile acids have either been attached to polymer backbones or chemically modified in order to produce polymerizable compounds for different biomedical applications [84]. Particles of poly(styrene) that were cross-linked with divinylbenzene, having several diameters, were synthesized with $0-15 \%$ of the chloromethylene groups being quaternized by the aminated derivatives of cholic acid. The rest were quaternized as ammonium groups, using triethylamine. Despite the low degree of functionalization, the authors suggested that the use of bile acid molecules as part of the polymer structure would lead to an enhanced binding capacity due to van der Waals interactions and/or hydrogen bonding interactions between the nearest-neighbors (Fig. 5) [82]. The binding capacity of the prepared BAS and the rate of release of bile salts were evaluated in the presence of sodium taurocholate, by ultraviolet (UV) spectroscopy. The capacity to bind taurocholate ions increased as the content of the tertiary amine derivative of cholic acid in the polymer matrix was increased. The kinetics of the taurocholate ions release process indicated that, besides the film diffusion process, the diffusion of ions within the polymer matrix (particle diffusion) plays an important role in the kinetic behavior [82].

As an alternative structure to BAS networks, Cameron and co-workers prepared new amphiphilic diblock copolymers $[40,85]$. These polymers contain hydrophobic segments and hydrophilic segments and can self-assemble in the presence of selective solvents, creating diverse micellar conformations. Such structures present a great surface area, which is able to provide a large number of binding sites for bile acid molecules. Also, the solutions of these amphiphilic structures, in comparison with those of the common polymer networks, possess lower viscosities, which can be seen as an advantage for patient compliance (less side effects such as constipation). The polymer studied was based on polystyrene (hydrophobic segment) and polyacrylamide (hydrophilic segment), functionalized with trimethylammonium methylene chloride [40]. The size and morphology of the micelles can be influenced by several parameters, such as the molecular weight distribution of the block copolymers, the temperature, the ionic strength and the $\mathrm{pH}$.

By varying the degree of polymerization of the copolymer segments, the authors were able to prepare BAS with different structures such as small spheres $(\sim 20 \mathrm{~nm})$, large micelles $(>100 \mathrm{~nm})$, vesicles and lamellae shapes, each confirmed by scanning electron microscopy (SEM) and transmission electron microscopy (TEM) analyses. The molecular weight of the polymers was controlled using anionic polymerization, which enabled the synthesis of well-defined copolymers, whose polydispersity was approximately 1.1 [40]. The authors obtained promising results, as seen in the fact that the micelles exhibited good stability and an ability to bind sodium glycocholate in sorption tests. However, the experimental steps that were involved in the polymerization and purification of the amphiphilic copolymers required complex and time-consuming procedures. Another important issue is the functionalization (amidation) step that needs to be 


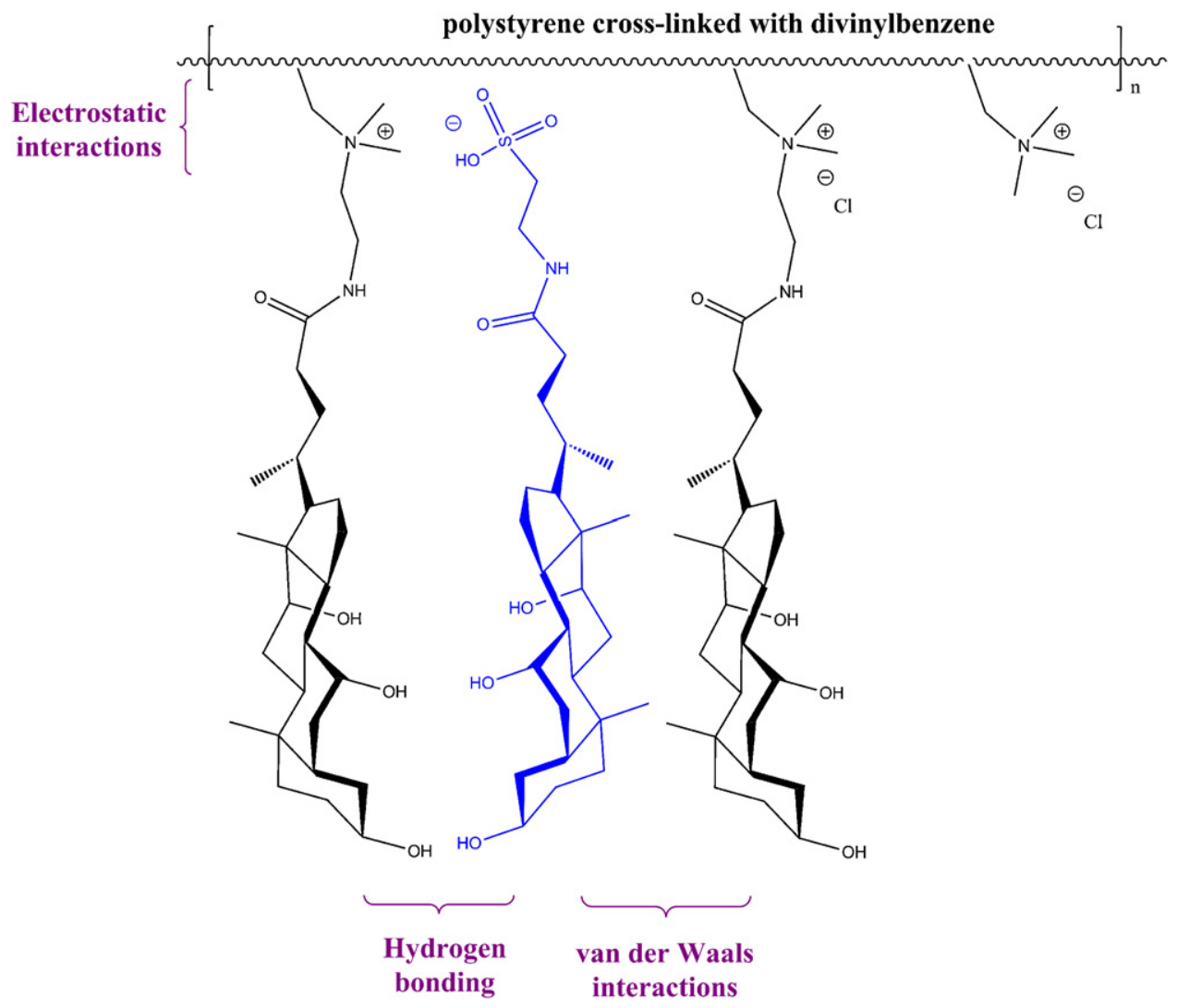

Fig. 5. Binding mechanism between bioconjugated based BAS and bile acids (blue), proposed by Zhang and co-workers [82]. (For interpretation of the references to color in this figure legend, the reader is referred to the web version of the article.)

optimized. The major advantages and disadvantages of the functionalization (amidation) step were explored: (i) direct reaction between the ester group and the amine or with an aluminum amide; (ii) hydrolysis of the ester groups to form carboxylic acids, followed by conversion into the corresponding acid chloride and reaction with an amine and (iii) hydrolysis of the ester groups to form carboxylic acids, followed by carbodiimide coupling to an amine [85]. Considering the complexity of the experimental conditions, the degree of functionalization achieved and the solubility of the polymers that were produced, together with issues related to reactivity and steric hindrance, the carbodiimide coupling route was the pathway that showed the greatest potential.

The same research group prepared a series of aminefunctionalized polymers, based on polyether backbones, in different solvents [86]. Poly(epichlorohydrin), with molecular weight of $700000 \mathrm{~g} / \mathrm{mol}$ was chemically modified with different low molecular weight amines, followed by crosslinking and alkylation to produce amphiphilic hydrogels. In a similar way, poly(2-chloroethyl vinyl ether) was produced by cationic polymerization and used as a backbone to create the final amine-functionalized cationic hydrogel. The introduction of desired functionalities in the polymers structure allowed the preparation of BAS with greater binding capacities towards bile acids compared to those of the commercially available cholestyramine and colestipol. However, the synthetic routes used required demanding experimental conditions, such as either a very high temperature or a very low temperature (e.g., $-70^{\circ} \mathrm{C}$ in cationic polymerization), long reaction times and the need for careful optimization of the poly(epichlorohydrin) modification step [86].

Some of the polymer modifications reported so far require time-consuming and complex experimental steps [14] and present a low efficiency of functionalization [68]. However, in the proper design of new BAS one must consider not only the final properties of the polymer, but also the method of synthesis. There is a need to establish relatively simple, but highly efficient and less expensive ways to prepare these materials. This is a critical issue in the development of new products that could have commercial impact and relevance.

An easier and somewhat novel strategy was followed by the same authors to synthesize BAS that were based on ammonium cyclic structures along the polymer backbone [19]. Such cationic hydrogels were prepared by cyclopolymerization using $\mathrm{N}$-substituted diallylammonium monomers (modified methyl diallylamine) followed by reaction with cross-linking monomers. A series of BAS with distinct hydrophilic properties were obtained by using different alkyl substituent groups in the methyl diallylamine modification step, as well as several cross-linking monomers in the final step of the reaction process (Fig. 6). The performance of these materials was monitored and evaluated by studying their aqueous swelling properties 

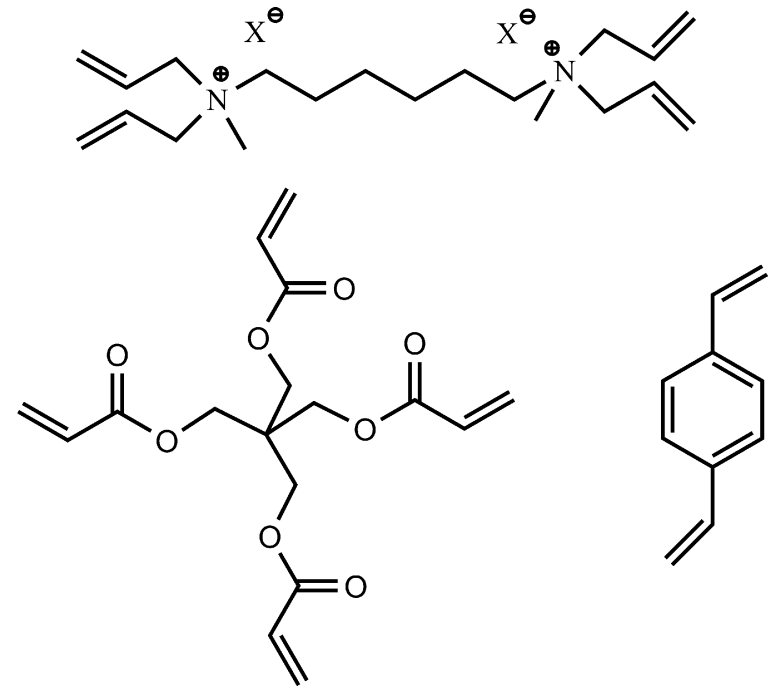

Fig. 6. Representative cross-linkers used in BAS synthesis [19].

and by the use of in vivo bile acids sequestration tests. Their strong binding capacity and their enhanced swelling properties were attributed to the more flexible hydrogels that were based on hydrophilic cross-linkers. Concerning the hydrophobic interactions, the authors proved that the BAS efficacy is not linearly dependent on the number of hydrophobic chains [19]. However, an optimum density of hydrophobic segments is required in order to maximize the binding capacity of the hydrogels.

Besides the chemical modification of polymer backbones, new strategies that are based on molecular imprinting have been proposed, showing interesting results with respect to the preparation of more effective BAS [87-89]. Using this technique, functional monomers are connected to a polymer backbone in the presence of template molecules. The functional groups or chemical structures that are present in the monomer must be able to interact with the template molecules in order to create a pre-polymerization complex [90]. The type of interactions (covalent or non-covalent interactions) that are established in the formation of the pre-polymerization complex gives the main difference between the two different molecular imprinting techniques, as reported in the literature (Fig. 7). Subsequently, after polymerization in the presence of a cross-linking monomer and a solvent, the template molecules are removed from the polymer, leaving specific cavities. This step can occur by chemical cleavage, in the case of covalent interaction with the pre-polymerization complex, or by solvent extraction via diffusion, when the template molecules are non-covalently bonded to the functional monomer. For this reason, non-covalent systems are the more widely used, even though their efficacy is less than that of covalent systems.

Molecular imprinting has been used in other biomedical applications for the preparation of appropriate polymer structures, in trying to mimic natural recognition systems $[90,91]$ and, recently, in hydrogel matrixes for drug delivery systems. Imprinted hydrogels, with their highly flexible polymer chains, which were believed to produce less efficient imprinted materials due to the high mobility of the created cavities, have been developed showing promising results [92]. Concerning these features, molecular imprinting could be also attractive for the preparation of BAS. In addition, the process provides a tailor-made component (the desired receptor), it is not expensive and does not require complex syntheses [93]. The use of bile acids as template molecules creates artificial recognition cavities in the BAS hydrogel. These could contribute to the enhancement of the binding forces during the bile acids sequestration process. This is the key factor to allowing the BAS polymers to compete with the desorbing forces that are present in the GI tract and preserve, at the same time, the bile acid molecules that are entrapped in their matrix.

Huval and co-workers proposed, for the first time, the synthesis of BAS that would be based on non-covalent molecular imprinting (Fig. 7) [81]. This strategy was intended to enhance the BAS binding capacity by creating complementary binding sites to the carboxyl groups that are present in bile acids as well as to the shape of the latter. Different polymer networks based on poly(allylammonium chloride) cross-linked with epichlorohydrin, were prepared, in the presence of the sodium salt of cholic acid, as a template (the bile salt that is more abundant in bile acids mixture). The sequestration capacity of the materials was tested in both in vitro experiments and in vivo experiments. Cholic acid-imprinted polymer networks showed a greater binding capacity towards bile acids, in both tests, in comparison to a control polymer hydrogel without template [81]. Moreover, the binding capacity increased with an increase in the cholic acid template content that was used in the imprinting, reaching $1.97 \mathrm{mmol} / \mathrm{g}$. These results show that the molecular imprinting technique could be useful for the preparation of BAS with enhanced binding capacity, since all of the polymer networks were prepared with the same cationic charge density (equivalent electrostatic interactions) and degree of cross-linking. These additional pieces of evidence to support the binding mechanism suggest that, besides being influenced by the electrostatic interactions and the hydrophobic interactions, the binding process can also be influenced by the shape-selective fitting of steroidal skeletons into complementary cavities, at least in the initial stage. After an initial binding of small amounts of the bile acid molecules by the imprinted BAS, the hydrophobic character of the aggregates increases, leading to stable structures that provide more affinity towards new bile acids molecules [81]. Similar results were obtained by Wang and colleagues [88] using a hybrid molecular imprinting approach. This hybrid method joins the major advantage of covalent molecular imprinting, which is the clear structure of the guestbinding site, with fast guest binding, that is characteristic of the non-covalent molecular imprinting method. The polymers were synthesized by covalent molecular imprinting, while the guest binding occurs by non-covalent interactions, which is characteristic of the non-covalent molecular imprinting technique [93].

Imprinted polymer networks have been synthesized by the free radical polymerization of a cholic acid-containing monomer, followed by cross-linking with ethylene 


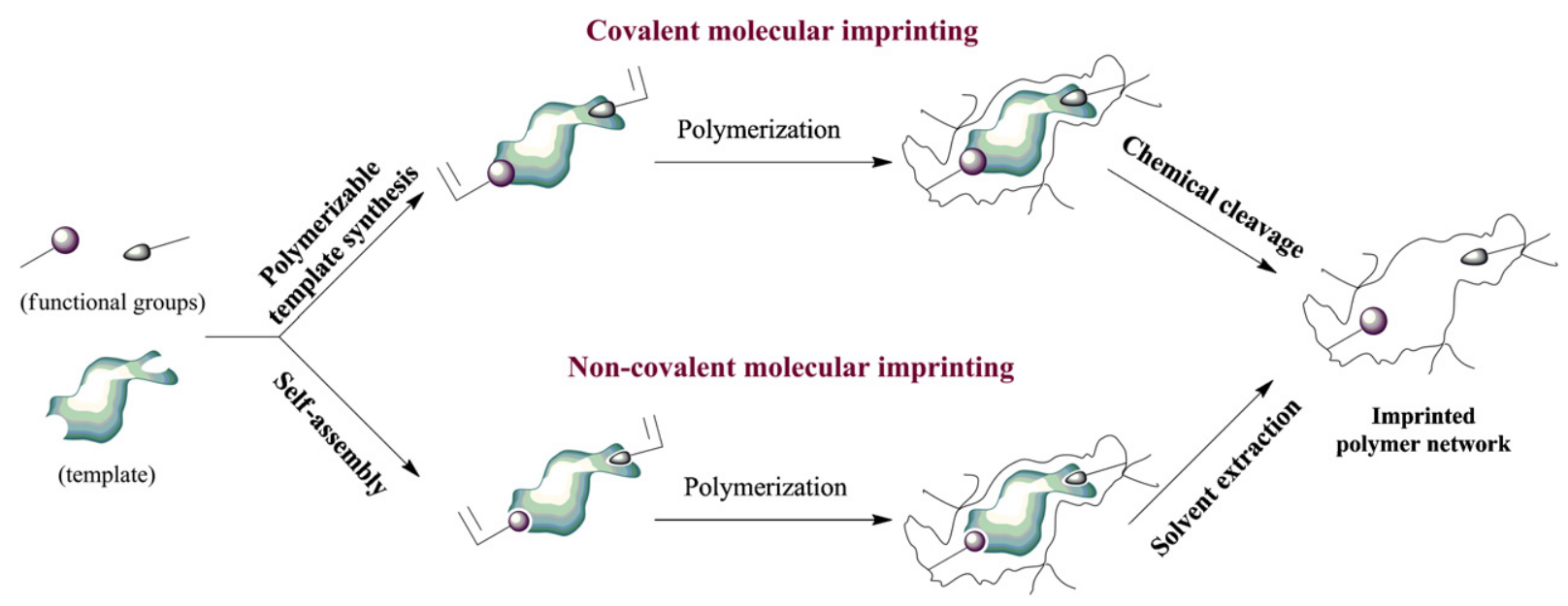

Fig. 7. Polymer molecular imprinting strategies.

glycol dimethacrylate [88]. The cholic acid complementary cavities were created by polymer hydrolysis (template cleavage), achieving only $45 \%$ of template removal efficiency. This step of chemical cleavage is somehow limiting since it is not possible to achieve high degrees of hydrolysis in cross-linked polymers because of steric hindrance factors [88], which restrict the number of specific interaction sites that are presented in the imprinted BAS. Nevertheless, the imprinted polymer networks that were prepared exhibited a nearly seven fold greater binding capacity value towards cholic acid and deoxycholic acid, in comparison to the binding capacity of the control sample (without the template). Besides the complementary cavities that were created in the hydrogel matrix, it was assumed that the entrapped molecules favored the binding process, since the binding capacity of the hydrogels was greater than the number of cavity sites. This observation arises from the co-operative effect of the bile acids molecules, that have a tendency to self-aggregate in aqueous media at high concentrations [81]. This result is extremely important and could provide useful information in further
BAS developments. In the same work [88], different polar solvents and non-polar solvents were tested as imprinting solvent. It was found that this self-aggregating parameter influenced the properties of the final hydrogels and ultimately influenced their binding capacity, showing that the use of non-polar solvents was preferable. Imprinted materials give better results when their polymerization takes place in solvents that mimic the final medium of the application [94]. BAS are intended to work in aqueous media, such as the intestine environment. However this solvent was not tested in the identified study. Water has some limitations when used in imprinting strategy, such as it can prevent hydrogen bonding between the template and the monomer. By this means, the capacity of recognition of the hydrogels could be compromised.

Despite the good results that were indicated by early reports on molecular imprinting, recent studies on the application of this technique to the synthesis of new BAS have shown that this approach would not be useful in some circumstances. Yañez and co-workers [89] have reported a computational modeling study of imprinted polymer

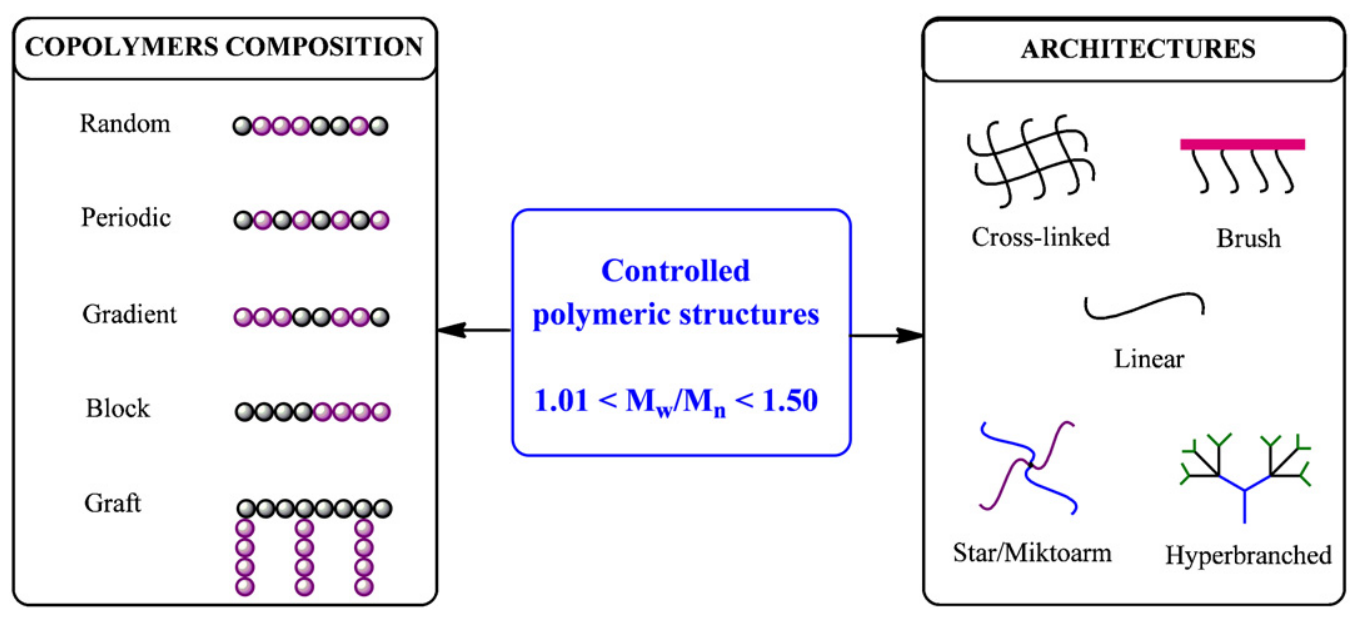

Fig. 8. Different polymer structures that can be produced by CLRP techniques. 
networks that were based on different functional acrylic monomers that possessed affinity towards cholic acid, with a cholic acid/functional monomer molar ratio of $1 / 4$. Several monomers that are commonly used in the preparation of BAS polymers were chosen and their binding energy with cholic acid molecules was estimated using computational modeling. After this screening, the authors selected three monomers, each one with a different binding affinity towards cholic acid, to assess experimentally their results with respect to the preparation of BAS imprinted hydrogels and their binding capacity towards sodium cholate. The results were in agreement with the theoretical predictions and suggested that the molecular imprinting technique is not so effective for polymers that already present high affinity towards the template molecules. It seems that in BAS polymers, this technique can only provide initial affinity towards bile acid molecules, being the main binding mechanism that is regulated by electrostatic interactions and hydrophobic interactions. This information is very relevant since it helps one to rule out some alternative possible synthetic approaches to the development of new BAS materials. Another parameter that was studied by the authors [89] was the influence of the polymer degree of cross-linking on the binding capacity. The results are consistent with the findings of reports presented in the literature [70], suggesting that there is an optimal degree of cross-linking that enables the targeted molecules to diffuse through the polymer matrix and reach the binding sites, while maintaining the polymer swelling characteristics. The ideal level of cross-linking with respect to maximizing the BAS efficacy is dependent on the polymer structure and on the molecular size of the targeted bile acid molecules. This study showed that computational modeling can be a very helpful tool in the design of new BAS, since it enables the screening of potential monomers to be used, taking into to account their ability to bind bile acids. This reduces the need to rely on time-consuming synthesis procedures and characterization tests in the search for new monomers that would be suitable for BAS preparation.

Despite the recent progress in the synthesis of new BAS, only a few products have been able to enter pre-clinical development stages and subsequent human clinical trials. More research is required to create ideal structures that can be more selective towards bile acid molecules, especially the more hydrophilic examples as the case of the trihydroxy bile acids. However, the studies reported in the literature provide important information concerning the variables that have to be taken into account in BAS design:

- Cationic groups: positive charges along the polymer structure ensure the occurrence of electrostatic interactions, which provide the primary mechanism of the binding process involving ionized bile acids;

- Hydrophobic chain length: longer aliphatic chains ensure the occurrence of hydrophobic interactions with the steroid skeletons of bile acids in the binding process;

- Degree of cross-linking and polymer backbone flexibility: lower cross-linking densities and flexible polymer backbones lead to enhanced swelling properties;
- Polymers shape: the use of appropriate polymer structures that can complement the bile acids architecture can favor the binding process.

It is noteworthy that these variables have to be adjusted on the basis of the nature of the polymers that are used in the synthesis of BAS.

\subsection{New approach towards well-defined bile acid sequestrants - "controlled"/living radical polymerization}

The appearance of methods that allow the control over polymer structure, architecture, topology, microstructure, composition and molecular weight, while using feasible experimental conditions, is an opportunity for the creation of new BAS materials and provides a basis for design of effective performance combinations. Nowadays, the main limitations concerning the use of polymers as effective therapeutics are based on the lack of control over the polymer properties due to either limitation of the polymerization methods (e.g., free radical polymerization (FRP)) and/or problems related to the proper functionalization of the synthesized polymers. In order to prepare reliable and effective therapeutic products, it is necessary to ensure, among other aspects, that the materials present homogenous properties. As discussed in Sections 3.1 and 3.2, the strategies used for BAS synthesis are mostly based on the chemical modification of polymers and/or the use of FRP techniques, which do not allow opportunities for the precise control of the structural characteristics of the resultant polymers. However, such control can be achieved by using advanced polymerization methods, namely CLRP. Due to its potential in the synthesis of well-defined polymers, CLRP methods have received huge attention by the scientific community since the mid-1990s [95]. Different CLRP methods are available, each having the common characteristic of providing the possibility of conducting a polymerization in which the termination reactions can be neglected and the resultant polymers present active terminal groups. The fundamental principles that govern the methods that are involved in CLRP have been comprehensively covered in several reviews [96-99]. CLRP can be applied to a wide range of monomers across diverse functionalities and offers the possibility to prepare complex polymer structures, such as stars and comb-like shapes, among others (Fig. 8) [99]. In addition, polymers prepared by CLRP can be easily functionalized with different pendant groups that can be further modified. The two techniques most commonly used for the synthesis of these complex structures are Atom Transfer Radical Polymerization (ATRP) and Reversible Addition-Fragmentation chain Transfer (RAFT) [95]. Recently, two reviews have reported the application of these techniques to the synthesis of biomaterials, including the use of functional cross-linked polymers $[100,101]$. Polymers prepared by CLRP can present several advantages in comparison with those obtained by conventional polymerization methods. For instance, star shaped polymers present lower viscosities than hydrogels that have high molecular weights, which can be a distinct advantage to many applications. Regarding hydrogels, it is possible, using CLRP, to obtain polymers with higher swelling 
<smiles></smiles>

PMTACA<smiles>CC(CSC(=S)SCCC(=O)OCCOC(C)(C)C)c1ccccc1</smiles>

PEO- $b$-PS<smiles>CCCCCCCCCCCNC(=O)C(C)CC(Br)C(=O)OCCN(C)C</smiles>

PDMAEA<smiles>CC(C)(CCC(=O)O)CC(C)(CC(C)(C)CSC(=S)c1ccccc1)C(=O)NCCC[N+](C)(C)CCC(=O)[O-]</smiles>

PCBMMA-3

Fig. 9. Examples of well-defined polymers produced by CLRP techniques: PMATCA poly[methacryloyl tri-(ethylene glycol) cholanoate] [111]; PDMAEA poly(2-(dimethylamino)ethyl acrylate) [110]; poly(3-methacryloylamino-propyl)-(2-carboxy-ethyl)-dimethylammonium (carboxybetaine methacrylamide) (PCBMAA-3) [106]; POE-b-PS - amphiphilic poly(ethylene oxide)-b-polysterene block copolymer [112].

ratios that those achieved using conventional polymerization methods and the same amounts of chemical reagents [95]. Moreover, graft copolymers with a precise number of branches per branch point and per branch point spacing can be prepared $[95,102]$. These features can be useful in helping to give an understanding of correlations between BAS structures and their mechanism of action, since it makes it possible to prepare a set of polymer samples that possess a portfolio of different structures and architectures from which one can determine and compare the relative efficacy.

It is well known that the design strategy for the creation of BAS must consider the chemical structure of the bile acids, their location, their concentration and the quantity of each that needs to be removed [3]. The use of CLRP techniques for the preparation of polymeric BAS could lead to the rational design of effective BAS materials. Functional polymers with targeted properties, such as their degree of functionalization, their macromolecular structure, their molecular weight and molecular weight distribution, can be prepared using straightforward experimental conditions. More important, living polymers present active chain-ends that can be further reinitiated, allowing the preparation of block copolymers with controlled composition (Fig. 8). Polymers that can be used as common BAS backbones (see Sections 3.1 and 3.2) have already been synthesized by CLRP techniques. These include amine/ammonium functionalized poly(styrene)s [103,104], poly(meth)acrylamides [105,106], poly(meth) acrylates [107-110] and polyethers. Polymer structures options include homopolymers and copolymers with complex architectures and controlled molecular weight. The incorporation of cholic acid molecules into polymer backbones, forming a comb-shaped polymer has also been reported [111]. Some illustrative examples of polymers 
that have been prepared by CLRP that could be used in BAS formulations are presented in Fig. 9.

CLRP is one of the more studied subjects in recent macromolecular science and the production of commercial, tailor-made polymeric materials is already a reality, including those for biomedical applications [113]. Many factors have contributed to this great achievement, namely the development of environmentally friendly systems, such as the use of small amounts of metal catalysts, aqueous media and ambient temperature processes [113]. The use of advanced polymerization methods will most probably lead to the development of a new generation of this class of polymer therapeutic materials.

\section{Summary and outlook}

BAS polymers constitute a type of polymer therapeutic material that can be applied in the treatment of hypercholesterolemia and type II diabetes. These materials interrupt the enterohepatic cycle by binding bile acids and remove them from the GI tract, which leads to plasma cholesterol levels decrease. BAS exhibit some important advantages over the conventional treatments involving the use of statins, namely the capacity of being non-absorbed by the systemic circulation. Currently, there are three available polymeric BAS in the US market, being Colesevelam the most effective one. However, more developments are needed in this area, since the commercial products still exhibit some undesirable side effects. Also, high dosages are required for effective treatments. This review reports the different synthetic approaches that are used in the development of new efficient BAS and the studies related to structure-binding capacity relationship. The parameters that were found to maximize the efficacy of BAS are (i) density of the cationic charges, in order to maintain electrostatic interactions with ionized bile acids, (ii) the presence of long hydrophobic segments, in order to ensure hydrophobic interactions with the steroid skeleton of bile acid molecules, (iii) the importance of polymer backbone flexibility and degree of cross-linking, to provide proper swelling characteristics and (iv) the fact that the polymer used can have a shape that is complementary to the shape of the bile acid molecules. Most of the synthetic routes that have been described are based on conventional polymerization techniques, which do not allow the precise control of the polymer features. However, this limitation could be overcome by using CLRP techniques, which allow the synthesis of "tailor-made" materials. These advanced polymerization techniques would lead to the development of a new generation of BAS. Moreover, it would be possible, for the first time, to establish important correlations between different polymer structures (varied systematically and stringently controlled) and their efficiency, with a view to the development of tailor-made BAS with their required, finely tuned properties.

\section{Acknowledgement}

Patrícia V. Mendonça acknowledges Fundação para a Ciência e Tecnologia (FCT-MCTES) for her PhD scholarship (SFRH/BD/69152/2010).

\section{References}

[1] Dhal P, Holmes-Farley S, Huval C, Jozefiak T. Polymers as drugs. In: Satchi-Fainaro R, Duncan R, editors. Polymer therapeutics I. Berlin/Heidelberg: Springer; 2006. p. 9-58.

[2] Duncan R. The dawning era of polymer therapeutics. Nature Reviews Drug Discovery 2003;2:347-60.

[3] Dhal PK, Huval CC, Holmes-Farley SR. Functional polymers as human therapeutic agents. Industrial and Engineering Chemistry Research 2005;44:8593-604

[4] Dhal PK, Polomoscanik SC, Avila LZ, Holmes-Farley SR, Miller RJ. Functional polymers as therapeutic agents: concept to market place. Advanced Drug Delivery Reviews 2009;61: 1121-30.

[5] Liu S, Maheshwari R, Kiick KL. Polymer-based therapeutics. Macromolecules 2009;42:3-13.

[6] Dhal PK, Huval CC, Holmes-Farley SR. Biologically active polymeric sequestrants: design, synthesis, and therapeutic applications. Pure and Applied Chemistry 2007;79:1521-30.

[7] Barker RH, Dagher R, Davidson DM, Marquis JK. Review article: tolevamer, a novel toxin-binding polymer: overview of preclinical pharmacology and physicochemical properties. Alimentary Pharmacology \& Therapeutics 2006;24:1525-34.

[8] Excellence SNIHC. Lipid modification (Guideline CG67): Cardiovascular risk assessment and the modification of blood lipids for the primary and secondary prevention of cardiovascular disease. Rockville MD: Agency for Healthcare Research and Quality (AHRQ); 2008, 11 pp.

[9] Reiner Ž, Catapano AL, De Backer G, Graham I, Taskinen M-R, Wiklund O, Agewall S, Alegria E, Chapman MJ, Durrington P, Erdine S, Halcox J, Hobbs R, Kjekshus J, Filardi PP, Riccardi G, Storey RF, Wood D. ESC/EAS Guidelines for the management of dyslipidaemias. European Heart Journal 2011;32:1769-818.

[10] Hou R, Goldberg AC. Lowering low-density lipoprotein cholesterol: statins, ezetimibe, bile acid sequestrants, and combinations: comparative efficacy and safety. Endocrinology and Metabolism Clinics of North America 2009;38:79-97.

[11] Staels B, Fonseca VA. Bile acids and metabolic regulation. Diabetes Care 2009;32:S237-45.

[12] Einarsson K, Ericsson S, Ewerth S, Reihnér E, Rudling M, Ståhlberg $\mathrm{D}$, Angelin B. Bile acid sequestrants: mechanisms of action on bile acid and cholesterol metabolism. European Journal of Clinical Pharmacology 1991;40:S53-8.

[13] Staels B, Handelsman Y, Fonseca V. Bile acid sequestrants for lipid and glucose control. Current Diabetes Reports 2010;10:70-7.

[14] Lee JK, Kim SY, Kim SU, Kim JH. Synthesis of cationic polysaccharide derivatives and their hypocholesterolaemic capacity. Biotechnology and Applied Biochemistry 2002;35:181-9.

[15] Zarras P, Vogl O. Polycationic salts as bile acid sequestering agents. Progress in Polymer Science 1999;24:485-516.

[16] Swaan PW, Szoka FC, Øie S. Use of the intestinal and hepatic bile acid transporters for drug delivery. Advanced Drug Delivery Reviews 1996;20:59-82.

[17] Insull W. Clinical utility of bile acid sequestrants in the treatment of dyslipidemia: a scientific review. Southern Medical Journal 2006;99:257-73.

[18] Mandeville WH, Goldberg DI. The sequestration of bile acids, a non-absorbed method for cholesterol reduction. A review. Current Pharmaceutical Design 1997;3:15-26.

[19] Huval CC, Holmes-Farley SR, Mandeville WH, Sacchiero R, Dhal PK. Syntheses of hydrophobically modified cationic hydrogels by copolymerization of alkyl substituted diallylamine monomers and their use as bile acid sequestrants. European Polymer Journal 2004;40:693-701.

[20] Gore MA, Kulkarni MGK. Bile acid sequestrants and process for preparation therefor. US Patent 0122375, Council of Scientific and Industrial Research; 2007.

[21] Mandeville WH, Holmes-Farley SR. Process for removing bile salts from a patient and alkylated compositions therefor. WO 95/34585, Geltex Pharmaceuticals; 1995.

[22] Holmes-Farley SR, Mandeville WH, Burke SK, Goldberg DI. Method for treating hypercholesterolemia with polyallylamine polymers. US Patent 6,423,754, Geltex Pharmaceuticals; 2002.

[23] Holmes-Farley SR, Dhal PK, Petersen JS. Poly-(diallylamine)-based bile acid sequestrants. US Patent 7,125,547, Genzyme Corporation; 2006.

[24] Anonymous. Drugs@FDA: FDA approved drug products. http://www.accessdata.fda.gov/scripts/cder/drugsatfda; 2011 [accessed Sep 2012]. 
[25] Asami T, Uchiyama M. Treatment of children with familial hypercholesterolemia with colestilan, a newly developed bile acidbinding resin. Atherosclerosis 2002;164:381-2.

[26] Sweetman SC, editor. Martindale: the complete drug reference. 37th ed. London: The Pharmaceutical Press; 2011. p. 4160.

[27] Nichifor M, Zhu XX, Baille W, Cristea D, Carpov A. Bile acid sequestrants based on cationic dextran hydrogel microspheres. 2 . Influence of the length of alkyl substituents at the amino groups of the sorbents on the sorption of bile salts. Journal of Pharmaceutical Sciences 2001;90:681-9.

[28] Primack WA, Gartner LM, McGurk HE, Spitzer A. Hyperchloremia and hypernatremia associated with cholestyramine therapy. Pediatric Research 1977;11:520-30.

[29] Harrold M. Antihyperlipoproteinemics and inhibitors of cholesterol biosynthesis. In: Lemke TL, Williams DA, editors. Foye's principles of medicinal chemistry. 6th ed. Philadelphia: Lippincott Williams \& Wilkins; 2007. p. 797-819.

[30] Honda Y, Nakano M. Studies on adsorption characteristics of bile acids and methotrexate to a new type of anionexchange resin, colestimide. Chemical and Pharmaceutical Bulletin 2000;48:978-81.

[31] Benson GM, Haynes C, Blanchard S, Ellis D. Invitro studies to investigate the reasons for the low potency of cholestyramine and colestipol. Journal of Pharmaceutical Sciences 1993;82:80-6.

[32] Pollex RL, Joy TR, Hegele RA. Emerging antidyslipidemic drugs. Expert Opinion on Emerging Drugs 2008;13:363-81.

[33] Alberto C, Eberhard W, Michel F. Colesevelam hydrochloride: usefulness of a specifically engineered bile acid sequestrant for lowering LDL-cholesterol. European Journal of Preventive Cardiology 2009;16:1-9.

[34] Davidson MH, Dillon MA, Gordon B, Jones P, Samuels J, Weiss S, Isaacsohn J, Toth P, Burke SK. Colesevelam hydrochloride (cholestagel): a new, potent bile acid sequestrant associated with a low incidence of gastrointestinal side effects. Archives of Internal Medicine 1999;159:1893-900.

[35] Steinmetz K. Colesevelam hydrochloride. American Journal of Health-System Pharmacy 2002;59:932-9.

[36] Matsuzaki Y. Colestimide: the efficacy of a novel anion-exchange resin in cholestatic disorders. Journal of Gastroenterology and Hepatology 2002;17:1133-5.

[37] Wu GM, Brown GR, St Pierre LE. Polymeric sorbents for bile acids. 5. Polyacrylamide resins with ammonium-containing pendants. Langmuir 1996;12:466-71.

[38] Huval CC, Holmes-Farley SR, Mandeville WH, Petersen JS, Sacchiero RJ, Maloney C, Dhal PK. Ammonium and guanidinium functionalized hydrogels as bile acid sequestrants: synthesis characterization, and biological properties. Journal of Macromolecular Science, Part A Pure and Applied Chemistry 2004;41: 231-44.

[39] Nichifor M, Zhu XX, Cristea D, Carpov A. Interaction of hydrophobically modified cationic dextran hydrogels with biological surfactants. Journal of Physical Chemistry B 2001;105: 2314-21.

[40] Cameron NS, Eisenberg A, Brown GR. Amphiphilic block copolymers as bile acid sorbents: 2 . Polystyrene-b-poly $(\mathrm{N}, \mathrm{N}, \mathrm{N}-$ trimethylammoniumethylene acrylamide chloride): self-assembly and application to serum cholesterol reduction. Biomacromolecules 2002;3:124-32.

[41] Anderson JW, Baird P, Davis Jr RH, Ferreri S, Knudtson M, Koraym A, Waters V, Williams CL. Health benefits of dietary fiber. Nutrition Reviews 2009;67:188-205.

[42] Brownlee IA. The physiological roles of dietary fibre. Food Hydrocolloids 2011;25:238-50.

[43] Chau CF, Huang YL, Lin CY. Investigation of the cholesterol-lowering action of insoluble fibre derived from the peel of Citrus sinensis L. cv. Liucheng. Food Chemistry 2004;87:361-6.

[44] Eastwood MA, Hamilton D. Studies on the adsorption of bile salts to non-absorbed components of diet. Biochimica et Biophysica Acta (BBA - Lipids and Lipid Metabolism 1968;152:165-73.

[45] Elhardallou S. The bile acids binding of the fibre-rich fractions of three starchy legumes. Plant Foods for Human Nutrition (Formerly Qualitas Plantarum) 1992;42:207-18.

[46] Hoagland PD. Binding of dietary anions to vegetable fiber. Journal of Agricultural and Food Chemistry 1989;37:1343-7.

[47] Kritchesvsky D. In vitro binding properties of dietary fibre. European Journal of Clinical Nutrition 1995;49:113-5.

[48] Buhman KK, Furumoto EJ, Donkin SS, Story JA. Dietary psyllium increases fecal bile acid excretion, total steroid excretion and bile acid biosynthesis in rats. Journal of Nutrition 1998;128:1199-203.
[49] Garcia-Diez F, Garcia-Mediavilla V, Bayon J. Pectin feeding influences fecal bile acid excretion, hepatic bile acid and cholestero synthesis and serum cholesterol in rats. Journal of Nutrition 1996;126:1766-71

[50] Kritchevsky D, Tepper SA. Influence of a fiber mixture on serum and liver lipids and on fecal fat excretion in rats. Nutrition Research 2005;25:485-9.

[51] Jenkins DJ, Kendall CW, Vuksan V. Viscous fibers, health claims, and strategies to reduce cardiovascular disease risk. American Journal of Clinical Nutrition 2000;71:401-2.

[52] Kendall CWC, Esfahani A, Jenkins DJA. The link between dietary fibre and human health. Food Hydrocolloids 2010;24:42-8.

[53] Brown L, Rosner B, Willett WW, Sacks FM. Cholesterol-lowering effects of dietary fiber: a meta-analysis. American Journal of Clinical Nutrition 1999;69:30-42.

[54] Van Rosendaal GM, Shaffer EA, Edwards AL, Brant R. Effect of time of administration on cholesterol-lowering by psyllium: a randomized cross-over study in normocholesterolemic or slightly hypercholesterolemic subjects. Nutrition Journal 2004;3, 17/1-7.

[55] Camire ME, Dougherty MP. Raisin dietary fiber composition and in vitro bile acid binding. Journal of Agricultural and Food Chemistry 2002;51:834-7.

[56] Kahlon TS, Smith GE. In vitro binding of bile acids by bananas, peaches, pineapple, grapes, pears, apricots and nectarines. Food Chemistry 2007;101:1046-51.

[57] Kahlon TS, Woodruff CL. In vitro binding of bile acids by soy protein, pinto beans, black beans and wheat gluten. Food Chemistry 2002;79:425-9

[58] Kongo-Dia-Moukala JU, Zhang H, Irakoze PC. In vitro binding capacity of bile acids by defatted corn protein hydrolysate. International Journal of Molecular Sciences 2011;12:1066-80.

[59] Dongowski G. Interactions between dietary fibre-rich preparations and glycoconjugated bile acids in vitro. Food Chemistry 2007; 104:390-7.

[60] Cornfine C, Hasenkopf K, Eisner P, Schweiggert U. Influence of chemical and physical modification on the bile acid binding capacity of dietary fibre from lupins (Lupinus angustifolius L.). Food Chemistry 2010;122:638-44.

[61] Kahlon TS, Chiu MCM, Chapman MH. Steam cooking significantly improves in vitro bile acid binding of beets, eggplant, asparagus, carrots, green beans, and cauliflower. Nutrition Research 2007;27:750-5.

[62] Kahlon TS, Chiu MCM, Chapman MH. Steam cooking significantly improves in vitro bile acid binding of collard greens, kale, mustard greens, broccoli, green bell pepper, and cabbage. Nutrition Research 2008;28:351-7.

[63] Zacheri C, Eisner P, Engel KH. In vitro model to correlate viscosity and bile acid-binding capacity of digested water-soluble and insoluble dietary fibres. Food Chemistry 2011;126:423-8.

[64] Cohn JS, Kamili A, Wat E, Chung RWS, Tandy S. Reduction in intestinal cholesterol absorption by various food components: Mechanisms and implications. Atherosclerosis Supplements 2010;11:45-8.

[65] Férézou J, Riottot M, Sérougne C, Cohen-Solal C, Catala I, Alquier C, Parquet M, Juste C, Lafont $H$, Mathé D, Corring T, Lutton C. Hypocholesterolemic action of beta-cyclodextrin and its effects on cholesterol metabolism in pigs fed a cholesterol-enriched diet. Journal of Lipid Research 1997;38:86-100.

[66] Riottot M, Olivier P, Huet A, Caboche JJ, Parquet M, Khallou J, Lutton C. Hypolipidemic effects of $\beta$-cyclodextrin in the hamster and in the genetically hypercholesterolemic rico rat. Lipids 1993;28:181-8.

[67] Trautwein EA, Forgbert K, Rieckhoff D, Erbersdobler HF. Impact of beta-cyclodextrin and resistant starch on bile acid metabolism and fecal steroid excretion in regard to their hypolipidemic action in hamsters. Biochimica et Biophysica Acta (BBA) - Molecular and Cell Biology of Lipids 1999;1437:1-12.

[68] Baille WE, Huang WQ, Nichifor M, Zhu XX. Functionalized betacyclodextrin polymers for the sorption of bile salts. Journal of Macromolecular Science, Part A Pure and Applied Chemistry 2000;37:677-90.

[69] Nichifor M, Cristea D, Carpov A. Sodium cholate sorption on cationic dextran hydrogel microspheres. 1. Influence of the chemical structure of functional groups. International Journal of Biological Macromolecules 2000;28:15-21.

[70] Nichifor M, Cristea D, Mocanu G, Carpov A. Aminated polysaccharides as bile acid sorbents: in vitro study. Journal of Biomaterials Science Polymer Edition 1998;9:519-34.

[71] Gallaher CM, Munion J, Hesslink R, Wise J, Gallaher DD. Cholestero reduction by glucomannan and chitosan is mediated by changes 
in cholesterol absorption and bile acid and fat excretion in rats. Journal of Nutrition 2000;130:2753-9.

[72] Hirano S, Itakura C, Seino H, Akiyama Y, Nonaka I, Kanbara N, Kawakami T. Chitosan as an ingredient for domestic animal feeds. Journal of Agricultural and Food Chemistry 1990;38:1214-7.

[73] Sugano M, Watanabe S, Kishi A, Izume M, Ohtakara A. Hypocholesterolemic action of chitosans with different viscosity in rats. Lipids 1988;23:187-91.

[74] Trautwein EA, Jürgensen U, Erbersdobler HF. Cholesterol-lowering and gallstone-preventing action of chitosans with different degrees of deacetylation in hamsters fed cholesterol-rich diets. Nutrition Research 1997; 17:1053-65.

[75] Zhou K, Xia W, Zhang C, Yu L. In vitro binding of bile acids and triglycerides by selected chitosan preparations and their physico-chemical properties. LWT-Food Science and Technology 2006;39:1087-92.

[76] Ikeda I, Sugano M, Yoshida K, Sasaki E, Iwamoto Y, Hatano K. Effects of chitosan hydrolyzates on lipid absorption and on serum and liver lipid concentration in rats. Journal of Agricultural and Food Chemistry 1993;41:431-5.

[77] Lee JK, Kim SU, Kim JH. Modification of chitosan to improve its hypocholesterolemic capacity. Bioscience, Biotechnology, and Biochemistry 1999;63:833-9.

[78] Murata Y, Kodoma Y, Hirai D, Kofugi K, Kawashima S. Properties of an oral preparation containing a chitosan salt. Molecules 2009;14:755-62.

[79] Kim CH, Chun HJ. A synthesis of O-diethylaminoethyl chitosan and its binding ability of cholate and deoxycholate anion in vitro. Polymer Bulletin 1999;42:25-32.

[80] Murata Y, Nagaki K, Kofuji K, Sanae F, Kontani H, Kawashima S. Adsorption of bile acid by chitosan salts prepared with cinnamic acid and analogue compounds. Journal of Biomaterials Science Polymer Edition 2006; 17:781-9.

[81] Huval CC, Bailey MJ, Braunlin WH, Holmes-Farley SR, Mandeville WH, Petersen JS, Polomoscanik SC, Sacchiro RJ, Chen X, Dhal PK. Novel cholesterol lowering polymeric drugs obtained by molecular imprinting. Macromolecules 2001;34:1548-50.

[82] Zhang LH, Janout V, Renner JL, Uragami M, Regen SL. Enhancing the "stickiness" of bile acids to cross-linked polymers: a bioconjugate approach to the design of bile acid sequestrants. Bioconjugate Chemistry 2000;11:397-400.

[83] Figuly GD, Royce SD, Khasat NP, Schock LE, Wu SLD, Davidson F, Campbell Jr GC, Keating MY, Chen HW, Shimshick EJ, Fischer RT, Grimminger LC, Thomas BE, Smith LH, Gillies PJ. Preparation and characterization of novel poly(alkylamine)-based hydrogels designed for use as bile acid sequestrants. Macromolecules 1997;30:6174-84.

[84] Zhu XX, Nichifor M. Polymeric materials containing bile acids. Accounts of Chemical Research 2002;35:539-46.

[85] Cameron NS, Eisenberg A, Brown GR. Amphiphilic block copolymers as bile acid sorbents: 1 . Synthesis of polystyrene-bpoly(N,N,N-trimethylammoniumethylene acrylamide chloride). Biomacromolecules 2002;3:116-23.

[86] Huval CC, Bailey MJ, Holmes-Farley SR, Mandeville WH, MillerGilmore K, Sacchiero RJ, Dhal PK. Amine functionalized polyethers as bile acid sequestrants: synthesis and biological evaluation. Journal of Macromolecular Science, Part A Pure and Applied Chemistry 2001;38:1559-74.

[87] Huval CC, Chen X, Holmes-Farley SR, Mandeville WH, Polomoscanik SC, Sacchiero RJ, Dhal PK. Molecularly imprinted bile acid sequestrants: synthesis and biological studies. In: Kofinas P, Roberts MJ, Sellergren B, editors. Molecularly imprinted materials-2003. Pittsburgh, PA: Materials Research Society; 2004. p. 85-90.

[88] Wang Y, Zhang J, Zhu XX, Yu A. Specific binding of cholic acid by cross-linked polymers prepared by the hybrid imprinting method. Polymer 2007;48:5565-71.

[89] Yanez F, Chianella I, Piletsky SA, Concheiro A, Alvarez-Lorenzo C. Computational modeling and molecular imprinting for the development of acrylic polymers with high affinity for bile salts. Analytica Chimica Acta 2010;659:178-85.

[90] Bergmann NM, Peppas NA. Molecularly imprinted polymers with specific recognition for macromolecules and proteins. Progress in Polymer Science 2008;33:271-88.

[91] Hillberg AL, Tabrizian M. Biomolecule imprinting: developments in mimicking dynamic natural recognition systems. IRBM 2008;29:89-104.
[92] Byrne ME, Salian V. Molecular imprinting within hydrogels. II: progress and analysis of the field. International Journal of Pharmaceutics 2008;364:188-212.

[93] Komiyama M, Takeuchi T, Mukawa T, Asanuma H. Molecular imprinting: from fundamentals to applications. Weinheim: WileyVCH Verlag GmbH \& Co.; 2004, pp.10-19.

[94] Wang NX, von Recum HA. Affinity-based drug delivery. Macromolecular Bioscience 2011:11:321-32.

[95] Gao HF, Matyjaszewski K. Synthesis of functional polymers with controlled architecture by CRP of monomers in the presence of cross-linkers: from stars to gels. Progress in Polymer Science 2009;34:317-50.

[96] Matyjaszewski K. Atom Transfer radical polymerization (ATRP): current status and future perspectives. Macromolecules 2012;45:4015-39.

[97] Moad G, Rizzardo E, Thang SH. Toward living radical polymerization. Accounts of Chemical Research 2008;41:1133-42.

[98] Matyjaszewski K. General concepts and history of living radical polymerization. In: Matyjaszewski K, Davis TP, editors. Handbook of radical polymerization. Hoboken: John Wiley \& Sons Inc.; 2002. p. 361-406.

[99] Braunecker WA, Matyjaszewski K. Controlled/living radical polymerization: features, developments, and perspectives. Progress in Polymer Science 2007;32:93-146.

[100] Boyer C, Bulmus V, Davis TP, Ladmiral V, Liu JQ Perrier S. Bioapplications of RAFT polymerization. Chemical Reviews 2009;109:5402-36.

[101] Xu FJ, Neoh KG, Kang ET. Bioactive surfaces and biomaterials via atom transfer radical polymerization. Progress in Polymer Science 2009;34:719-61.

[102] Uhrig D, Mays J. Synthesis of well-defined multigraft copolymers. Polymer Chemistry 2011:2:69-76.

[103] Postma A, Davis TP, Evans RA, Li GX, Moad G, O'Shea MS. Synthesis of well-defined polystyrene with primary amine end groups through the use of phthalimido-functional RAFT agents. Macromolecules 2006;39:5293-306.

[104] Toquer G, Monge S, Antonova K, Blanc C, Nobili M, Robin JJ. Synthesis via ATRP and anchoring properties of ammonium-terminated monofunctional or telechelic polystyrenes. Macromolecular Chemistry and Physics 2007;208:94-102.

[105] Grassl B, Clisson G, Khoukh A, Billon L. Nitroxide-mediated radical polymerization of acrylamide in water solution. European Polymer Journal 2008;44:50-8

[106] Rodriguez-Emmenegger C, Schmidt BVKJ, Sedlakova Z, Subr V, Bologna Alles A, Brynda E, Barner-Kowollik C. Low temperature aqueous living/controlled (RAFT) polymerization of carboxybetaine methacrylamide up to high molecular weights. Macromolecular Rapid Communications 2011;32:958-65.

[107] Coelho JFJ, Carvalho EY, Marques DS, Popov AV, Percec V, Goncalves PMFO, Gil MH. Synthesis of poly(ethyl acrylate) by single electron transfer-degenerative chain transfer living radical polymerization in water catalyzed by $\mathrm{Na}_{2} \mathrm{~S}_{2} \mathrm{O}_{4}$. Journal of Macromolecular Science, Part A Pure and Applied Chemistry 2008;46:421-32.

[108] Coelho JFJ, Gois J, Fonseca AC, Carvalho RA, Popov AV, Percec V, Gil MH. Synthesis of poly(2-methoxyethyl acrylate) by single electron transfer-degenerative transfer living radical polymerization catalyzed by $\mathrm{Na}_{2} \mathrm{~S}_{2} \mathrm{O}_{4}$ in water. Journal of Macromolecular Science, Part A Pure and Applied Chemistry 2009;47:4454-63.

[109] Coelho JFJ, Silva AMFP, Popov AV, Percec V, Abreu MV, Goncalves PMOF, Gil MH. Single electron transfer-degenerative chain transfer living radical polymerization of $\mathrm{N}$-butyl acrylate catalyzed by $\mathrm{Na}_{2} \mathrm{~S}_{2} \mathrm{O}_{4}$ in water media. Journal of Macromolecular Science, Part A Pure and Applied Chemistry 2006;44:2809-25.

[110] Ding SJ, Floyd JA, Walters KB. Comparison of surface confined ATRP and SET-LRP syntheses for a series of amino (meth)acrylate polymer brushes on silicon substrates. Journal of Macromolecular Science, Part A Pure and Applied Chemistry 2009;47:6552-60.

[111] Hao JQ, Li H, Zhu XX. Preparation of a comb-shaped cholic acid-containing polymer by atom transfer radical polymerization. Biomacromolecules 2006; 7:995-8.

[112] Hossain MD, Tran LTB, Park JM, Lim KT. Facile synthesis of core-surface crosslinked nanoparticles by interblock RAFT polymerization. Journal of Macromolecular Science, Part A Pure and Applied Chemistry 2010;48:4958-64.

[113] Destarac M. Controlled radical polymerization: industrial stakes, obstacles and achievements. Macromolecular Reaction Engineering 2010;4:165-79. 